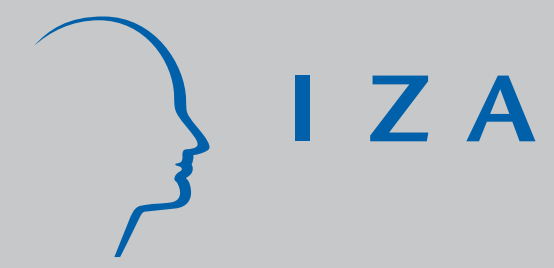

IZA DP No. 1882

Do Former College Athletes Earn More at Work?

A Nonparametric Assessment

Daniel J . Henderson

Alexandre Olbrecht

Solomon Polachek

December 2005 


\title{
Do Former College Athletes Earn More at Work? A Nonparametric Assessment
}

\author{
Daniel J. Henderson \\ State University of New York at Binghamton \\ Alexandre Olbrecht \\ Ramapo College of New Jersey at Mahwah \\ Solomon Polachek \\ State University of New York at Binghamton \\ and IZA Bonn
}

Discussion Paper No. 1882

December 2005

\author{
IZA \\ P.O. Box 7240 \\ 53072 Bonn \\ Germany \\ Phone: +49-228-3894-0 \\ Fax: +49-228-3894-180 \\ Email: iza@iza.org
}

\begin{abstract}
Any opinions expressed here are those of the author(s) and not those of the institute. Research disseminated by IZA may include views on policy, but the institute itself takes no institutional policy positions.
\end{abstract}

The Institute for the Study of Labor (IZA) in Bonn is a local and virtual international research center and a place of communication between science, politics and business. IZA is an independent nonprofit company supported by Deutsche Post World Net. The center is associated with the University of Bonn and offers a stimulating research environment through its research networks, research support, and visitors and doctoral programs. IZA engages in (i) original and internationally competitive research in all fields of labor economics, (ii) development of policy concepts, and (iii) dissemination of research results and concepts to the interested public.

IZA Discussion Papers often represent preliminary work and are circulated to encourage discussion. Citation of such a paper should account for its provisional character. A revised version may be available directly from the author. 
IZA Discussion Paper No. 1882

December 2005

\section{ABSTRACT \\ Do Former College Athletes Earn More at Work? A Nonparametric Assessment}

This paper investigates how students' collegiate athletic participation affects their subsequent labor market success. It uses newly developed distributional tests to establish that the wage distribution of former college athletes is significantly different from non-athletes and that athletic participation is a significant determinant of wages. Additionally, by using newly developed techniques in nonparametric regression, it shows that on average former college athletes earn a wage premium. However, the premium is not uniform, but skewed so that more than half the athletes actually earn less than non-athletes. Further, the premium is not uniform across occupations. Athletes earn more in the fields of business, military, and manual labor, but surprisingly, athletes are more likely to become high school teachers, which pays a relatively lower wage to athletes. We conclude that nonpecuniary factors play an important role in occupational choice, at least for many former collegiate athletes.

JEL Classification: $\quad \mathrm{C} 14, \mathrm{J10}, \mathrm{J30}, \mathrm{J40}, \mathrm{L} 83$

Keywords: nonparametric, generalized Kernel estimation, wage determination, earnings, sports economics, athletics

Corresponding author:

Solomon Polachek

Department of Economics

State University of New York at Binghamton

Binghamton, New York 13902

USA

Email: polachek@binghamton.edu 


\section{Introduction}

National Collegiate Athletic Association (NCAA) Division I-A athletic departments lose an average of $\$ 600,000$ per year on revenues of $\$ 25,100,000$, after subtracting institutional support. Similarly, in 2001, NCAA Division I-AA and I-AAA schools lost on average $\$ 3,390,000$ and $\$ 2,820,000$, respectively. Although numbers were not directly reported, Division II and III schools also sustained losses, though smaller in magnitude (see the 2001 NCAA Revenues and Expenses Report). Indeed, of the 1,266 colleges and universities participating in the membership led organization of the NCAA, which serves almost 350,000 student-athletes, only 41 athletic departments showed a profit in 2001.

For the mere 3.23 percent of profitable NCAA members, the revenue sports of football and basketball are primarily responsible. Revenues generated by these two sports are large enough to offset the expenses incurred in all the other sports supported by those particular athletics departments. At lower NCAA levels, football and basketball are also money-losing sports partly because post-season appearance prizes and national television contracts are nonexistent. Other than some Division I-A football, Division I basketball and ice hockey programs, collegiate athletic teams, regardless of the division of competition, have expenses that exceed revenues.

If athletics are for the most part "money losing," there must be reasons why universities fund these endeavors. Among the reasons given are institutional and instructional arguments concerning what players learn. For example, successes of athletic programs may cause a university's image to increase and lead to a higher number of applications. Because academic reputation is partially based upon the number of applications and acceptance rates, this may help improve a university's standing. Athletic success may even lead to an increase in donations. Generally, lower division teams do not receive national acclaim but such schools may also view financial losses as an investment in the future (for example if a school plans to move up to Division I).

Athletes are also said to learn valuable life lessons from athletic participation. Student athletes may learn skills that will be useful later in the labor market. For the

small percentage of individuals who have realistic expectations of playing professional sports, athletic participation may be viewed as an investment in their future careers. 
The majority of the investment type arguments are anecdotal in nature because earnings data that also records athletic participation in college are rare.

The only known exception is Long and Caudill (1991), hereafter LC. They argue that athletic participation is a form of human capital investment because athletic participation teaches athletes added discipline, teamwork skills, a strong drive to succeed and a better work ethic. ${ }^{1}$ If these student athletes gain more skills (or if student athletes use collegiate sports to improve their existing skills), then all else constant, one would expect participation in college athletics to yield a wage premium when compared to non-athletes with similar demographic and academic ability characteristics.

Using a maximum likelihood procedure that deals with the limited dependent variable problem, LC estimate a wage function and find that former male athletes six years after expected college graduation earned approximately a $\$ 650$ (or approximately 4 percent) wage premium in 1980. Although popular, maximum likelihood techniques require several restrictive assumptions. First, the errors are assumed to come from a particular distribution. Further, the functional form for the technology is given a priori. These are both very strong assumptions, which may or may not be correct. For example, if one chooses a specific technology, and that assumption is false, estimation will most likely lead to biased estimates. Partly for these reasons, we adopt a nonparametric approach which addresses these concerns. ${ }^{2}$

Nonparametric estimation procedures relax the functional form assumptions associated with the traditional parametric regression model and create a tighter fitting regression curve through the data. These procedures do not require assumptions on the distribution of the error nor do they require specific assumptions on the form of the underlying technology. Further, the procedures generate unique coefficient estimates for each observation for each variable. This attribute enables us to estimate the earnings benefit of athletic participation for each individual.

Although nonparametric techniques are attractive, issues employing the proce-

\footnotetext{
${ }^{1}$ Several studies have focused on the effects of high school athletics participation on earnings (e.g., Ewing 1995) using the National Longitudinal Survey of Youth and the National Longitudinal Survey of the High School Class of 1972. These surveys did not ask about collegiate participation.

${ }^{2}$ Nonparametric and semiparametric estimation have been used in other labor economics domains to avoid restrictve functional form assumptions. As an example regarding how policies to reform personal income tax affect the speed of labor supply adjustment, see Kniesner and Li (2002).
} 
dures arise with this and similar data sets. Here the complication occurs because most nonparametric techniques require the variables to be continuous. This is problematic for us because of the abundance of ordered and unordered categorical variables in the only available data set on college athletes that contain post college earnings. As will be explained, to get around the nonparametric estimation problems encountered when having categorical data, we apply the Li-Racine Generalized Kernel Estimation procedure, which unlike most other nonparametric procedures, can smooth categorical variables.

In implementing the empirical procedure, we first establish that the wage distributions between former athletes and non-athletes are significantly different. Second, we make a statistical argument that athletic participation is a determining factor of the wage distribution. We then apply the Generalized Kernel Estimation procedure to get at the main contribution of this paper, which is to investigate the occupations in which athletes receive a wage premium. We find that former college athletes receive a wage premium in business, manual labor and military occupations, but former athletes who select high school teaching as an occupation are linked with lower wages, ceteris paribus.

If these wage premiums for specific occupations are known to individuals, one would expect former college athletes to be more likely to enter a particular field where they may have a wage advantage over non-athletes. To test this premise, we further extend LC's work by using logit models to test if athletic participation helps predict occupational choice. Our findings suggest that college athletic participation is a positive factor in selecting a high school teaching occupation, but seemed not to influence any other occupational choices. Although it may seem to be irrational behavior for former athletes to be more likely to select a particular job associated with lower wages, non-pecuniarious factors could be responsible.

\section{Methodology}

\section{$2.1 \quad$ Model}

Generally economists estimate an earnings function to investigate how an independent variable affects earnings. In our particular case, we are interested in understanding 
the role of collegiate athletics on earnings and would like to estimate the widely used parametric specification of the earnings function

$$
w_{i}=f\left(x_{i}, \beta\right)+\varepsilon_{i}, \quad i=1,2, \ldots, N
$$

where $w_{i}$ (measured in logs) is a directly observable and continuous wage variable for each individual $i, x$ is a $N \times p$ matrix of exogenous control variables (for example, athlete), $\beta$ is a $p \times 1$ vector of parameters to be estimated, and $\varepsilon_{i}$ is the random disturbance. If the dependent variable and the residuals are well-behaved, estimation by ordinary least squares is appropriate.

Unfortunately, in our data we face a limited dependent variable problem. As will be explained later, wages in this data set are reported as income categories, with the highest bracket having no upper bound. Since OLS results would be biased because the error terms no longer have zero expectations, LC select a method developed by Nelson (1976). Nelson's Maximum Likelihood procedure, to which both probit and logit models are special cases, handles the problems associated with limited dependent variables of the above nature. However, as stated previously, Nelson's methodology requires one to make assumptions regarding both the functional form for the technology and the distribution of the error term. In addition, the procedure gives a single coefficient estimate for each variable. This implicitly assumes that the return to each variable is constant across individuals, which also may or may not be true.

\subsection{Generalized Kernel Estimation}

Given the limitations of Nelson's procedure, we adopt a nonparametric approach. In this section, we describe Li-Racine Generalized Kernel Estimation (see Li and Racine 2004 and Racine and Li 2004), which will be used in order to estimate the returns to collegiate athletic participation. First, consider the nonparametric regression model

$$
w_{i}=m\left(x_{i}\right)+\varepsilon_{i}, \quad i=1, \ldots, N,
$$

where $m$ is the unknown smooth earnings function with argument $x_{i}=\left[x_{i}^{c}, x_{i}^{u}, x_{i}^{o}\right]$, $x_{i}^{c}$ is a vector of continuous regressors (for example, standardized test scores), $x_{i}^{u}$ is a vector of regressors that assume unordered discrete values (for example, athlete), $x_{i}^{o}$ 
is a vector of regressors that assume ordered discrete values (for example, number of children), $\varepsilon$ is an additive error, and $N$ is the number of individuals in the sample. Taking a first-order Taylor expansion of (2) with respect to $x_{j}$ yields

$$
w_{i} \approx m\left(x_{j}\right)+\left(x_{i}^{c}-x_{j}^{c}\right) \beta\left(x_{j}\right)+\varepsilon_{i},
$$

where $\beta\left(x_{j}\right)$ is defined as the partial derivative of $m\left(x_{j}\right)$ with respect to $x^{c}$. Here, if $w_{i}$ is the log wage, the estimated coefficient of $\beta\left(x_{j}\right)$ is interpreted as the return to wages for a given $x^{c}$, specific to each individual $i$.

The estimator of $\delta\left(x_{j}\right) \equiv\left(\begin{array}{c}m\left(x_{j}\right) \\ \beta\left(x_{j}\right)\end{array}\right)$ is given by

$$
\begin{aligned}
& \widehat{\delta}\left(x_{j}\right)=\left(\begin{array}{l}
\widehat{m}\left(x_{j}\right) \\
\widehat{\beta}\left(x_{j}\right)
\end{array}\right)=\left[\sum_{i} K_{\lambda}\left(\begin{array}{cc}
1 & \left(x_{i}^{c}-x_{j}^{c}\right) \\
\left(x_{i}^{c}-x_{j}^{c}\right) & \left(x_{i}^{c}-x_{j}^{c}\right)\left(x_{i}^{c}-x_{j}^{c}\right)^{\prime}
\end{array}\right]^{-1}\right. \\
& \sum_{i} K_{\lambda}\left(\begin{array}{c}
1 \\
\left(x_{i}^{c}-x_{j}^{c}\right)
\end{array}\right) w_{i},
\end{aligned}
$$

where $K_{\lambda}=\prod_{s=1}^{q} \widehat{\lambda}_{s}^{c}{ }^{-1} l^{c}\left(\frac{x_{s i}^{c}-x_{s j}^{c}}{\hat{\lambda}_{s}^{c}}\right) \prod_{s=1}^{r} l^{u}\left(x_{s i}^{u}, x_{s j}^{u}, \widehat{\lambda_{s}^{u}}\right) \prod_{s=1}^{p} l^{o}\left(x_{s i}^{o}, x_{s j}^{o}, \widehat{\lambda_{s}^{o}}\right) . K_{\lambda}$ is the commonly used product kernel (see Pagan and Ullah 1999), where $l^{c}$ is the standard normal kernel function with window width $\lambda_{s}^{c}=\lambda_{s}^{c}(N)$ associated with the $s^{\text {th }}$ component of $x^{c} . l^{u}$ is a variation of Aitchison and Aitken's (1976) kernel function which equals one if $x_{s i}^{u}=x_{s j}^{u}$ and $\lambda_{s}^{u}$ otherwise, and $l^{o}$ is the Wang and Van Ryzin (1981) kernel function which equals one if $x_{s i}^{o}=x_{s j}^{o}$ and $\left(\lambda_{s}^{o}\right)\left|x_{s i}^{o}-x_{s j}^{o}\right|$ otherwise.

Estimation of the bandwidths $\left(\lambda^{c}, \lambda^{u}, \lambda^{o}\right)$ is typically the most salient factor when performing nonparametric estimation. For example, choosing a very small bandwidth means that there may not be enough points for smoothing and thus we may get an undersmoothed estimate (low bias, high variance). On the other hand, choosing a very large bandwidth, we may include too many points and thus get an oversmoothed estimate (high bias, low variance). This trade-off is a well known dilemma in applied nonparametric econometrics and thus we resort to automatic determination procedures to estimate the bandwidths. Although there exist many selection methods, one popular procedure (and the one used in this paper) is that of Least-Squares CrossValidation (LSCV). In short, the procedure chooses $\left(\lambda^{c}, \lambda^{u}, \lambda^{o}\right)$ which minimize the least-squares cross-validation function given by

$$
C V\left(\lambda^{c}, \lambda^{u}, \lambda^{o}\right)=\frac{1}{N} \sum_{j=1}^{N}\left[w_{j}-\widehat{m}_{-j}\left(x_{j}\right)\right]^{2},
$$


where $\widehat{m}_{-j}(\cdot)=H y_{j}$ is the commonly used leave-one-out estimator of $m(x) .^{3}$

Finally, casual observation of (4) shows that estimates of $\beta\left(x_{j}\right)$ are obtained only for the continuous regressors. The returns to the categorical variables must be obtained in a separate step. For the unordered categorical variables, for example, the coefficient on ATHLETE $=1$ is calculated as the counterfactual increase in the expected wage of a particular individual when they go from not being a collegiate athlete to being a collegiate athlete, ceteris paribus. Similarly for the ordered categorical variables, for example, the coefficient on $N C H I L D R E N=1$ is calculated as the counterfactual increase in the expected wage of a particular individual when you increase the number of children they have from zero to one, ceteris paribus. At the same time, NCHILDREN $=2$ would show the counterfactual increase in the expected wage of a particular individual when you increase the number of children from zero to two, ceteris paribus. If the linear structure is appropriate (parametric dummy variable approach), one would expect the coefficient on $N C H I L D R E N=2$ to be twice that of $N C H I L D R E N=1$. This is often not the case. See Hall, Racine and $\mathrm{Li}$ (2004), Li and Ouyang (2005), Li and Racine (2004, 2005) and Racine and Li (2004) for further details.

\section{Data}

The Cooperative Institutional Research Survey (CIRP) collected information from college freshmen (both men and women) in the 1970-1971 academic year, and included one follow-up in 1980, six years after expected collegiate graduation (see Astin 1982). Respondents were asked a variety of questions pertaining to demographic factors, including family income and background, college majors, athletic participation in high school, race and goals considered important, during their first year of college. The follow-up questionnaire asked respondents about their lives after college, including earnings (in categories), occupational choices, graduate degrees attained and athletic participation in college (definitions for all variables can be found in Appendix A).

Because the purpose of the paper is to examine the role of athletic participation on earnings, it is important for included individuals to have had an opportunity to

\footnotetext{
${ }^{3}$ All bandwidths in this paper were calculated using $\mathrm{N}$ (C).
} 
participate in sports. At the time information was collected, females still lacked full enforcement of Title IX, which requires gender equality in sports, and as a result, females were not included because of the limited number of female athletes. Dropping women from the sample left 4,209 males, of which 646 (approximately 16 percent) were considered athletes in our data. Individuals responding in the affirmative to the question of whether they earned a varsity letter in college were assigned a value of one for the collegiate athletic participation variable, ATHLETE, and zero otherwise. Information on which sport or division the individual participated in was not collected.

College athletes participating in "big-time" athletics programs could be seen as training for a professional career in athletics and would earn wages significantly higher than non-athletes if they attained their career goal. If enough individuals worked in that profession, there could be an upward bias on the athletic participation coefficient. However, LC believe that it is unlikely that these individuals attended schools to train for a professional career. Their main argument was that the profile of the schools attended by the athletes in this sample did not match with the expected profile of a school with "big time" athletics. Specifically, as shown by Table 1, former college athletes attended smaller enrollment schools than non-athletes. Although a somewhat weak assumption, we feel that even if some athletes attended larger schools, this will not be the source of any bias. ${ }^{4}$ The other source of concern with this data deals with the reporting of the dependent variable.

As previously stated, income was reported as a limited dependent variable. The variable was reported in intervals defined in the following manner: $1=\$ 1$ to $\$ 6,999$, $2=\$ 7,000$ to $\$ 9,999,3=\$ 10,000$ to $\$ 14,999,4=\$ 15,000$ to $\$ 19,999,5=\$ 20,000$ to $\$ 24,999,6=\$ 25,000$ to $\$ 29,999,7=\$ 30,000$ to $\$ 34,999,8=\$ 35,000$ to $\$ 39,999$, and $9=\$ 40,000$ or more. The distribution of athletes and non-athletes across income intervals is not identical. Table 2, and Figure 1 show that a slightly higher percentage of athletes are in the higher income brackets, which most likely accounts for the slightly higher average wage enjoyed by athletes.

\footnotetext{
${ }^{4}$ Only one athlete in the sample was in the highest income bracket and had an occupation listed as "other." Professional athletes would be expected to be in the highest income bracket and select an occupation of "other." Using the preceding criteria, it is unlikely any of the remaining former college athletes were professional athletes.
} 
In addition to income, Table 1 shows that athletes seem to enjoy a slight advantage in certain other categories. A higher percentage of athletes completed their bachelors, masters, and doctoral or professional degrees. Athletes were more likely to attend a private institution and reported themselves to be on average more driven and more likely to have a goal to be well-off financially compared to non-athletes. Neither group had a significant average advantage regarding ACT scores and course grades, but choice of school and motivation seemed to differ between the two groups. They were less likely than non-athletes to want to own their own business. Each of these variables were included as control variables because individuals with a strong competitive drive, a goal to be financially well-off and a motivation to own their own business would be expected to earn higher wages, ceteris paribus. In the statistical analysis to follow, possessing these traits might also make it more likely for an individual to play competitive athletics and failure to address these traits could cause a bias in the coefficient of the ATHLETE variable.

\section{Results}

\subsection{Distribution Tests}

Before jumping into the regression, we feel it necessary to perform two distributional tests. First, we want to establish that the distribution of wages between athletes and non-athletes are significantly different from one another. Second, we will test whether the distribution of wages is dependent on athletic participation. Performing these tests not only strengthen the argument for inclusion of the ATHLETE variable on the right hand side of our wage regression, but it makes the argument that athletic participation has a significant impact on the wages of former college students.

There are a number of kernel based tests for the equality of distributions (for example see Li 1996), however, generally they require that the underlying variable of interest is continuous in nature. As previously stated, the variable of interest is ordered and categorical, and thus any kernel based test used requires a kernel function equipped for discrete data. For this reason, we select the Li, Maasoumi, and Racine (2004) nonparametric test for equality of distributions with mixed categorical and continuous data. In our particular case, we are interested in testing whether 
the probability density function of wages for former college athletes is significantly different from that of non-athletes. Intuitively, if the null hypothesis is rejected, then an investigation of why these two distributions are significantly different may be warranted. With this data, we firmly reject the null hypothesis ( $\mathrm{p}$-value $=0.0071$ ).

After establishing a statistical difference between two wage distributions, it is prudent to test whether explanatory variables have a deterministic effect on the distribution of wages. The question now becomes, does athletic participation influence the distribution of wages? If the ATHLETE variable is found to significantly affect the stability of the conditional probability density function, then a strong argument can be made as to why this variable should be included in the wage regression. Here we employ Racine's (2002) invariance test. This test examines the validity of the null hypothesis, which states that an underlying distribution does not change with particular values of a conditioning variable. To test the null, a gradient is constructed using kernel estimates of the conditional PDF with respect to the conditioning variable of interest, namely the ATHLETE variable. Intuitively, if we reject the null hypothesis, it is agreed that athletic participation has a statistically significant effect on the distribution of wages. We find that it does by rejecting the null at the one percent level of significance ( $\mathrm{p}$-value $=0.0005$ ).

\subsection{Regression Results}

When encountering a situation in which a regression must be estimated using a limited dependent variable, econometricians often use an ordered logit model. ${ }^{5}$ However, using this method not only requires several restrictive assumptions, but it also limits discussion to calculating self determined marginal effects and makes it difficult to investigate the returns to athletic participation for specific occupations. The nonparametric method we use allows for a more straightforward and flexible interpretation of the regression coefficients estimated.

Given the number of parameters obtained from the Generalized Kernel Estimation procedure, it is tricky to present results. Unfortunately no widely accepted presentation format exists. Therefore, in Figure 2, we give the mean and the 25th, 50th and

\footnotetext{
${ }^{5}$ When estimating an ordered logit model while using the same setup as LC, a coefficient of .269 (standard error of .078) for the ATHLETE variable is obtained.
} 
75th percentile (labelled Quartile 1, 2 and 3) along with their respective bootstrapped standard errors as well as a kernel density plot of the coefficients for the athletic participation variable for each athlete included in the data set (by definition the athletic participation coefficient for all non-athletes is zero). Each coefficient represents the impact on earnings (category) for a one unit increase of the associated independent variable (in other words, ATHLETE going from 0 to 1). ${ }^{6}$

One consideration is important in interpreting the ATHLETE coefficient. For the coefficient to be unbiased, ATHLETE must be truly exogenous - implying athletic status must be randomly assigned. However, it is possible students become athletes because they are innately motivated and disciplined - qualities that are unobservable but positively correlated with earnings (Duncan and Dunifon 1998). If this is the case, athletes may earn more not because universities provide value-added, but because better students become athletes. There are two ways to get at this potential bias, though each is imperfect. One possibility is to model athletic participation using a selection rule, and then account for this selectivity in the earnings equation (Willis and Rosen 1979). For this approach to work one ideally should identify factors that affect athletic prowess such as height and weight (unavailable in the data) but that are unrelated to earnings. The problem finding such variables is at best tricky. Participating in high school athletics is a possibility, but this variable imperfectly predicts collegiate athletic participation and besides may be correlated with earnings. A second, but also imperfect, approach is to include motivational variables in the original earnings function in order to hold constant the type "drive" that inspires athletes but also raises earnings. We adopt this latter approach because the data contain two such variables: first, a dummy categorical variable indicating whether the respondent rates himself in the highest $10 \%$ in "drive and ambition" (Drive Dummy); and second, a dummy categorical variable indicating that being "well-off financially is an important goal" (Well Dummy). Perhaps more importantly, because our true goal is to compare our nonparametric approach to LC, we follow their lead to treat ATHLETE as exogenous by assuming innate athletic ability to be a god-given talent.

The mean of the coefficients for the ATHLETE variable, 0.028, indicates that

\footnotetext{
${ }^{6}$ The mean coefficient values for the remaining regressors are qualitatively similar to the results in LC. They are available from the authors upon request.
} 
former college athletes are in a 0.028 higher earnings category than non-athletes, ceteris paribus. Because most income categories represent a $\$ 5,000$ wage gap, this coefficient can be interpreted as approximately a $\$ 140$ wage benefit. Although qualitatively similar, this is smaller than the four percent premium reported by LC. But the variation in individual wage premiums is more interesting. Less than half the college athletes actually receive a positive gain. The median of the coefficients (Q2) is negative, implying a skewed distribution with more than half of former college athletes actually earning lower wages than non-athletes, ceteris paribus.

Discussing individual variation in parameter values is one of the major benefits we gain by using the nonparametric technique. Although we found that on average athletes obtain a wage premium, we were able to show that over half of them did not. Simply stereotyping all athletes under one estimate is misleading. For example, the typical parametric approach, such as used by LC suggest that athletes earn higher wages than non-athletes, ceteris paribus. If individuals choosing whether or not to participate in college athletics take this information as given, it could affect their decision making. Given the positive coefficient on ATHLETE found by LC, individuals may decide to participate in sports because they believe that their wages will rise in the future. Similarly, universities may opt for sports programs believing that individual students necessarily benefit. However, our result shows that the wage premium is not uniform across athletes. Although some athletes enjoy large wage benefits, others earn less than non-athletes. Thus, for students, the more appropriate question is not whether to participate in sports, but the more specific question should be, if an individual participates in a sport, in which occupations will that individual most likely earn a wage premium over non-athletes?

Table 3 shows the estimates on the ATHLETE variable for four job categories; as well as for a fifth category depicting all other occupations combined. The four occupations, high school teaching, business, military, and manual labor are ones with a significant number of former athletes (arbitrarily chosen as those occupations with at least 35 athletes). For the latter three occupations (business, military, and manual labor), the mean and median are positive, indicating that a wage premium is present for a majority of athletes in those occupations. Intuitive arguments could be made that skills obtained or improved during athletic participation would justify wage 
premiums in these occupations. Teamwork skills and an enhanced competitive drive to succeed could be useful in the business world. Physical strength and other athletic attributes may make manual laborers and military professionals more productive at their jobs, justifying higher wages. The ability to apply strategic thinking and adjust a particular strategy during a game may be particularly important while using military tactics, may be important during a business negotiation, or may be important when operating as a team to perform some physical task. Many of these reasons apply to the conglomerate occupation, as well.

Although most job categories were associated with wage premiums, the high school teaching occupation was not. In teaching, a majority of former college athletes earn lower wages, ceteris paribus, as compared to non-athletes in this category. Although we will shortly discuss potential explanations of this observation, a wage premium can affect occupational choice. Specifically one would expect former athletes to enter jobs where they earn high wages and shy away from jobs where they do not. But this is not the case for athletes.

Table 4 reports the results of a logit model where the binary dependent variable, HSTEACHER, takes a value one if an individual reported high school teaching as an occupation, zero otherwise. In this data, former college athletes were found to be more likely to select high school teaching as an occupation, despite earning lower wages. Similarly, we found this result to hold on population subsamples such as for African Americans. Several arguments can be levied to explain this behavior, but no evidence in the data clearly supports any claim in particular.

First, becoming a teacher may be driven by a non-pecuniary desire for upward social mobility. Falk, Falkowski and Lyson (1981), and Schwarzweller and Lyson (1978) report that the highly respected teaching profession is a source of upward social and professional intergenerational mobility for rural whites and African Americans, especially during the 1970s. If athletes are more likely to be motivated to improve their lives, they may have viewed a teaching profession as a means to improve their status in life. The teaching occupation generally provides fewer barriers to entry and as a governmental organization is not allowed by law to discriminate against any particular group. The accessibility and attractiveness of teaching may explain why African American former college athletes are more likely to choose this profession. 
Several other theories are worth mentioning. If athletics fosters an increased affection for a school, then an athlete may wish to return to his high school to work. Athletes may also wish to pursue coaching. Because high school teachers often serve as coaches, this desire may be reflected in their occupational choice decision. Even if former athletes choosing this profession realize they will be expected to earn lower average wages, the increased utility generated by coaching may offset any monetary losses.

Regardless of the reason(s) for becoming teachers, a relatively large supply of former athletes could exert downward wage pressure in the teaching occupation. If a labor market is inordinately supplied with individuals possessing similar traits, then that group's wages could be lower than comparably skilled workers in other markets. For example, if many former athletes are trying to become physical education teachers, then the wages of physical education teachers could be lower than other teachers.

\section{Conclusion}

Estimating the impact of individual behavior is an important aspect of social research. Often outcome can be measured in monetary units. When this is the case, one can estimate an earnings function to determine how an individual's actions affect his or her earnings. In most cases, parametric models are used. However, parametric models have certain restrictions regarding functional form. In addition, they are usually specified in ways to yield a single coefficient estimate.

One such example is the effect of a student's participation in college athletics on earnings years after leaving college, a topic not well studied because of the paucity of data. However, in one such study Long and Caudill (1991) find that college athletes earn about a $4 \%$ positive return from collegiate sports. Because of certain data restrictions (a categorical dependent variable) they use Nelson's (1976) maximum likelihood procedure, but as with most such parametric procedures that paper limits itself to obtaining a single coefficient without exploring how robust their findings are across the population.

This paper reexamines the issue using a new technique. The Li-Racine Generalized Kernel Estimation procedure is able to assess the impact of an exogenous variable 
within a model containing an ordered categorical dependent variable along with continuous, unordered, and ordered categorical regressors. Of course, the beauty of the technique is its ability to estimate coefficients for each individual so that one can assess the impact of athletic participation across the sample.

This paper examines the CIRP data. Unlike past studies, we find that the wage premiums associated to former college athletes are not uniform. Rather, athletes earn between a 1.5 and 9 percent average wage premium in business, manual labor and military careers, but nonetheless enter teaching occupations with a higher probability than non-athletes despite facing an average wage deficiency of 8 percent. Whereas wage premiums in the former three occupations conform to the human capital type matching models of occupational choice, the latter result regarding teaching are consistent with non-pecuniary incentives explaining occupational choice. This latter result regarding non-pecuniary motivators imply broader implications than usually inferred from typical economics models based solely on pecuniary factors.

Institutions of higher education need good reasons when deciding how to spend limited funds. If a financial value can be linked to athletics, a stronger argument may be employed to justify investment in athletics programs. This paper argues that financial benefits are not uniform to all individuals who play sports. On average athletes receive a modest return and go into occupations where they do best. But this is not the case for all collegiate athletes. Almost $10 \%$ enter teaching, an occupation with an especially low wage for athletes. Further, a good $50 \%$ do no better than the college population at large. 


\section{References}

[1] Aitchison, J. and C. G. G. Aitken (1976). "Multivariate Binary Discrimination by the Kernel Method," Biometrika, 63, 413-20.

[2] Astin, A. (1982). Minorities in American Higher Education, Jossey-Bass, San Francisco.

[3] Duncan, G. J. and R. Dunifon (1998). "'Soft-Skills' and Long-Run Labor Market Success," Research in Labor Economics, 17, 123-49.

[4] Ewing, B. (1995). "High School Athletics and the Wages of Black Males," Review of Black Political Economy, 24, 65-78.

[5] Falk, W. W., C. Falkowski,and T. A. Lyson (1981). "Some Plan to Become Teachers': Further Elaboration and Specification," Sociology of Education, 54, 64-9.

[6] Hall, P., J. Racine and Q. Li (2004). "Cross-Validation and the Estimation of Conditional Probability Densities," Journal of The American Statistical Association, 99, 1015-26.

[7] Kniesner, T. and Q. Li (2002). "Nonlinearity in Dynamic Adjustment: Semiparametric Estimation of Panel Labor Supply," Empirical Economics, 27, 131-48.

[8] Li, Q. (1996). "Nonparametric Testing of Closeness between Two Unknown Distribution Functions," Econometric Reviews, 15, 261-74.

[9] Li, Q. and D. Ouyang (2005). "Uniform Convergence Rate of Kernel Estimation with Mixed Categorical and Continuous Data," Economics Letters, 86, 291-6.

[10] Li, Q., E. Maasoumi and J. Racine (2004). "A Nonparametric Test for the Equality of Distributions With Mixed Categorical and Continuous Data," manuscript, Syracuse University.

[11] Li, Q. and J. Racine (2003). "Nonparametric Estimation of Distributions with Categorical and Continuous Data," Journal of Multivariate Analysis, 86, 266-92. 
[12] Li, Q. and J. Racine (2004). "Cross-Validated Local Linear Nonparametric Regression," Statistica Sinica, 14, 485-512.

[13] Li, Q. and J. Racine (2005). Nonparametric Econometrics: Theory and Practice, Princeton, Princeton University Press, (forthcoming).

[14] Long, J. and S. Caudill (1991). "The Impact of Participation in Intercollegiate Athletics on Income and Graduation," Review of Economics and Statistics, 73, 525-31.

[15] N (c), Nonparametric software by Jeff Racine (http://www.economics.mcmaster.ca/racine/).

[16] NCAA (2004). "Revenues and Expenses of Intercollegiate Athletics Programs" and "NCAA Facts," (http://www.ncaa.org).

[17] Nelson, F. (1976). "On a General Computer Algorithm for the Analysis of Models with Limited Dependent Variables," Annals of Economic and Social Measurement, 493-509.

[18] Pagan, A. and A. Ullah (1999). Nonparametric Econometrics, Cambridge University Press, Cambridge.

[19] Racine, J. (2002). "A Consistent Nonparametric Distributional Invariance Test," manuscript, Syracuse University.

[20] Racine, J. and Q. Li (2004). "Nonparametric Estimation of Regression Functions with Both Categorical and Continuous Data," Journal of Econometrics, 119, 99130 .

[21] Schwarzweller, H. K. and T. A. Lyson (1978). "Some Plan to Become Teachers: Determinants of Career Specification among Rural Youths in Norway, Germany, and the United States," Sociology of Education, 51, 29-43.

[22] Wang, M. C. and J. Van Ryzin (1981). "A Class of Smooth Estimators for Discrete Estimation," Biometrika, 68, 301-9. 
[23] Willis, R. J. and S. Rosen (1979). "Education and Self-Selection," Journal of Political Economy, 87: S7-36. 
Table 1: Descriptive Statistics for CIRP Data

\begin{tabular}{lcccc}
\hline \hline \multicolumn{1}{l}{ Variable } & Non-Athletes (Nn = 3563) & \multicolumn{3}{c}{ Athletes (Na = 646) } \\
\hline Income (Bracket) & Mean & Standard Deviation & Mean & Standard Deviation \\
Income (in Dollars) & 4.685 & 1.605 & 4.854 & 1.516 \\
ACT Score & 18025 & & 19270 & 3.785 \\
African American & 23.030 & 3.889 & 23.889 & 0.383 \\
Bachelors Degree & 0.127 & 0.333 & 0.178 & 0.495 \\
Drive Dummy & 0.521 & 0.500 & 0.576 & 0.477 \\
Family Dummy & 0.280 & 0.449 & 0.348 & 0.461 \\
Firm Size & 0.267 & 0.443 & 0.305 & 1.722 \\
Grades & 4.040 & 1.756 & 4.141 & 1.030 \\
Married & 4.459 & 1.107 & 4.430 & 0.506 \\
Masters Degree & 0.502 & 0.500 & 0.156 & 0.363 \\
Number of Children & 0.143 & 0.350 & 0.364 & 0.708 \\
Part-Time Employed & 0.385 & 0.728 & 0.050 & 0.217 \\
Ph.D. or Professional Degree & 0.068 & 0.251 & 0.105 & 0.307 \\
Private & 0.086 & 0.281 & 0.738 & 0.440 \\
Runbus & 0.578 & 0.494 & 0.149 & 0.356 \\
School Enrollment & 0.165 & 0.371 & 4.717 & 1.650 \\
Self Employed & 5.374 & 1.871 & 0.037 & 0.189 \\
Veteran & 0.054 & 0.169 & 0.006 & 0.079 \\
Well Dummy & 0.029 & 0.351 & 0.161 & 0.368 \\
\hline \hline NOTES: Descrition & 0.144 & & \\
\hline
\end{tabular}

NOTES: Descriptions of each variable are provided in the Appendix A and income brackets are described in Table 2. 
Table 2: Income Brackets

\begin{tabular}{|c|c|c|c|c|c|}
\hline Income Brackets & Income & Non-Athletes & $\%$ of Non-Athletes & Athletes & $\%$ of Athletes \\
\hline$\$ 1$ to $\$ 6,999$ & 1 & 378 & 10.61 & 48 & 7.43 \\
\hline$\$ 7,000$ to $\$ 9,999$ & 2 & 308 & 8.64 & 53 & 8.20 \\
\hline$\$ 10,000$ to $\$ 14,999$ & 3 & 999 & 28.04 & 163 & 25.23 \\
\hline$\$ 15,000$ to $\$ 19,999$ & 4 & 921 & 25.85 & 177 & 27.40 \\
\hline$\$ 20,000$ to $\$ 24,999$ & 5 & 569 & 15.97 & 138 & 21.36 \\
\hline$\$ 25,000$ to $\$ 29,999$ & 6 & 231 & 6.48 & 38 & 5.88 \\
\hline$\$ 30,000$ to $\$ 34,999$ & 7 & 84 & 2.36 & 17 & 2.63 \\
\hline$\$ 35,000$ to $\$ 39,999$ & 8 & 20 & 0.56 & 6 & 0.93 \\
\hline$\$ 40,000$ or more & 9 & 53 & 1.49 & 6 & 0.93 \\
\hline
\end{tabular}

NOTES: Individuals reported which income bracket they belong to amongst the listed categories. Individuals who reported no income were dropped from the sample. 
Table 3: Wage Premiums for Select Occupations

\begin{tabular}{|c|c|c|c|c|c|c|c|c|}
\hline Occupation & Mean & Q1 & $\mathrm{Q} 2$ & Q3 & $\mathrm{Nn}$ & Wage (n) & $\mathrm{Na}$ & Wage (a) \\
\hline \multirow[t]{2}{*}{ High School Teacher } & -0.0550 & -0.0882 & -0.0313 & -0.0021 & 190 & 3.96 & 66 & 3.87 \\
\hline & $0.0006^{*}$ & $0.0007^{*}$ & $0.0002 *$ & $0.0002 *$ & & & & \\
\hline \multirow[t]{2}{*}{ Business } & 0.0643 & -0.1658 & 0.0018 & 0.0643 & 1144 & 5.13 & 187 & 5.37 \\
\hline & $0.0005 *$ & $0.0005 *$ & $0.0000 *$ & $0.0005^{*}$ & & & & \\
\hline \multirow[t]{2}{*}{ Military } & 0.0169 & -0.0887 & 0.0478 & 0.2149 & 169 & 4.69 & 35 & 5.00 \\
\hline & $0.0008 *$ & $0.0007 *$ & $0.0002 *$ & $0.0021 *$ & & & & \\
\hline \multirow[t]{2}{*}{ Manual Labor } & 0.0809 & -0.0905 & 0.0265 & 0.2073 & 605 & 4.36 & 67 & 4.53 \\
\hline & $0.0010 *$ & $0.0005 *$ & $0.0002 *$ & $0.0150 *$ & & & & \\
\hline \multirow[t]{2}{*}{ All Other Occupations } & 0.0188 & -0.1199 & 0.0001 & 0.1380 & 1455 & 4.59 & 291 & 4.80 \\
\hline & $0.0008^{*}$ & $0.0018^{*}$ & 0.0001 & $0.0018^{*}$ & & & & \\
\hline \multirow[t]{2}{*}{ All Occupations } & 0.0280 & -0.1150 & -0.0070 & 0.1480 & 3563 & 4.69 & 646 & 4.85 \\
\hline & $0.0019 *$ & $0.0001^{*}$ & $0.0002 *$ & $0.0020 *$ & & & & \\
\hline
\end{tabular}

NOTES: The values listed in the table refer to the coefficient on the ATHLETE variable. Bootstrapped standard errors are shown in italics. The asterisk $(*)$ signifies that the point estimate is significant at the $5 \%$ level. Nn and Na refer to the number of non-athletes and athletes in a particular group, respectively. Similarly, Wage (n) and Wage (a) refer to the average wage for non-athletes and athletes in a particular group, respectively. 
Table 4: Logit Model -- Determinants of Becoming a High School Teacher

\begin{tabular}{lcc}
\hline \hline Variable & Estimate & Standard Error \\
\hline Intercept & -3.097 & 0.740 \\
ACT Score & -0.059 & $0.026^{*}$ \\
African American & -0.040 & 0.260 \\
Bachelor's Degree & 2.424 & $0.434^{*}$ \\
Drive Dummy & 0.154 & 0.175 \\
Firm Size & -0.130 & $0.051^{*}$ \\
Grades & 0.128 & 0.092 \\
High School Athlete & 0.846 & $0.172^{*}$ \\
Major1 & -0.878 & $0.465^{*}$ \\
Major10 & -1.094 & 0.762 \\
Major11 & -1.455 & $0.544^{*}$ \\
Major2 & -1.094 & $0.238^{*}$ \\
Major3 & -0.851 & $0.294^{*}$ \\
Major4 & -3.336 & $0.477^{*}$ \\
Major5 & -3.308 & $0.732^{*}$ \\
Major6 & -1.263 & $0.298^{*}$ \\
Major7 & -1.937 & $0.741^{*}$ \\
Major8 & -14.891 & 561.8 \\
Major9 & -1.694 & $0.243^{*}$ \\
Married & 0.122 & 0.174 \\
Master's Degree & 2.467 & $0.466^{*}$ \\
Number of Children & -0.181 & 0.137 \\
Ph.D. or Professional Degree & 0.257 & 0.743 \\
Private & 0.110 & 0.226 \\
Runbus & -0.938 & $0.304^{*}$ \\
School Enrollment & 0.020 & 0.057 \\
Veteran & -0.178 & 0.547 \\
\hline \hline NOTES: The depentent varian & &
\end{tabular}

NOTES: The dependent variable in this logit regression is the High

School Teaching Occupation. See Appendix A for descrptions of each of the variables. See Appendix $\mathrm{C}$ for the definitions of the academic fields constituting each major. The asterisk (*) signifies that the estimate is significant at the $5 \%$ level. 
Figure 1: Kernel Distributions of Income Brackets

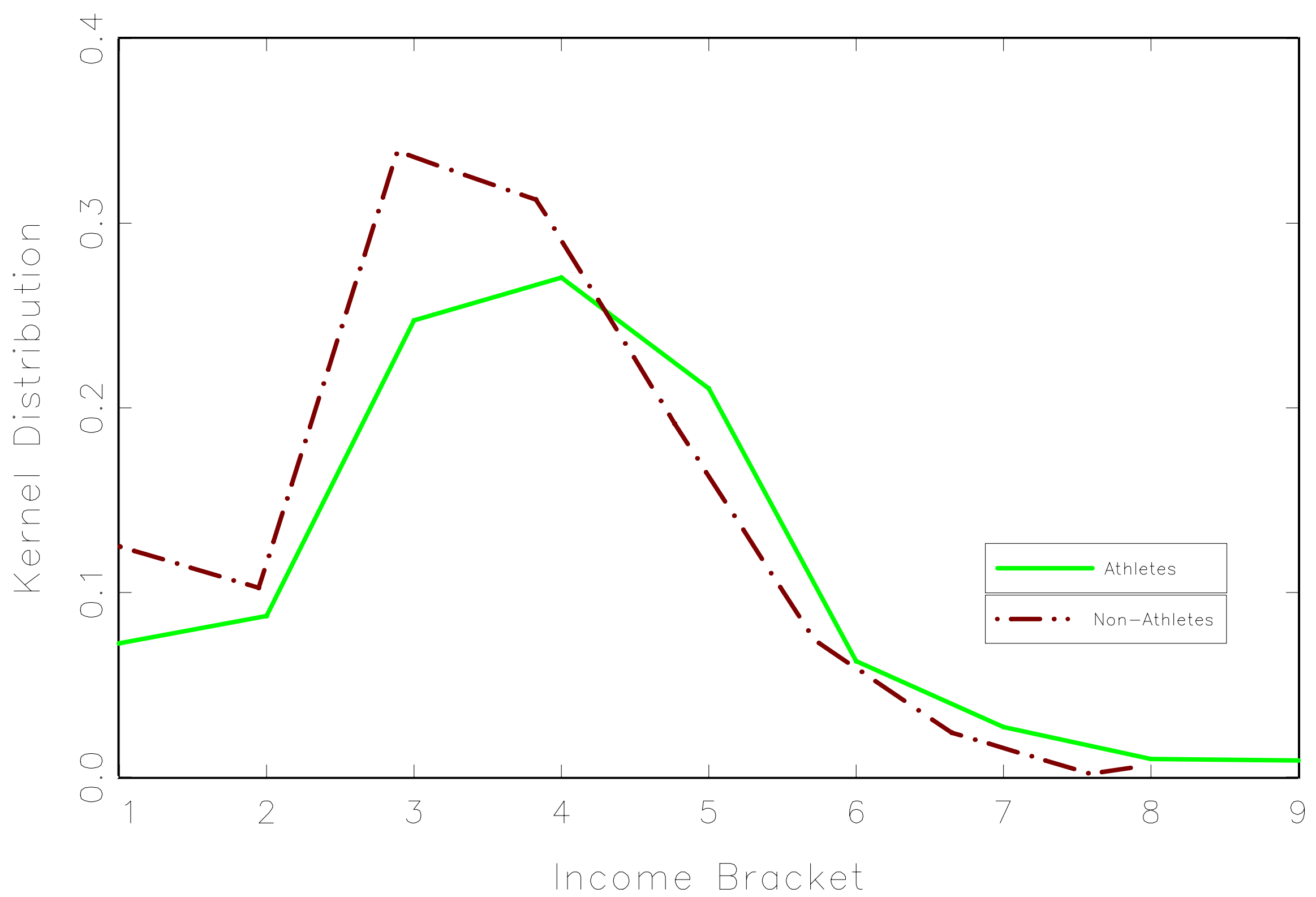


Figure 2: Kernel Distribution of Athletic Wage Premium Coefficients

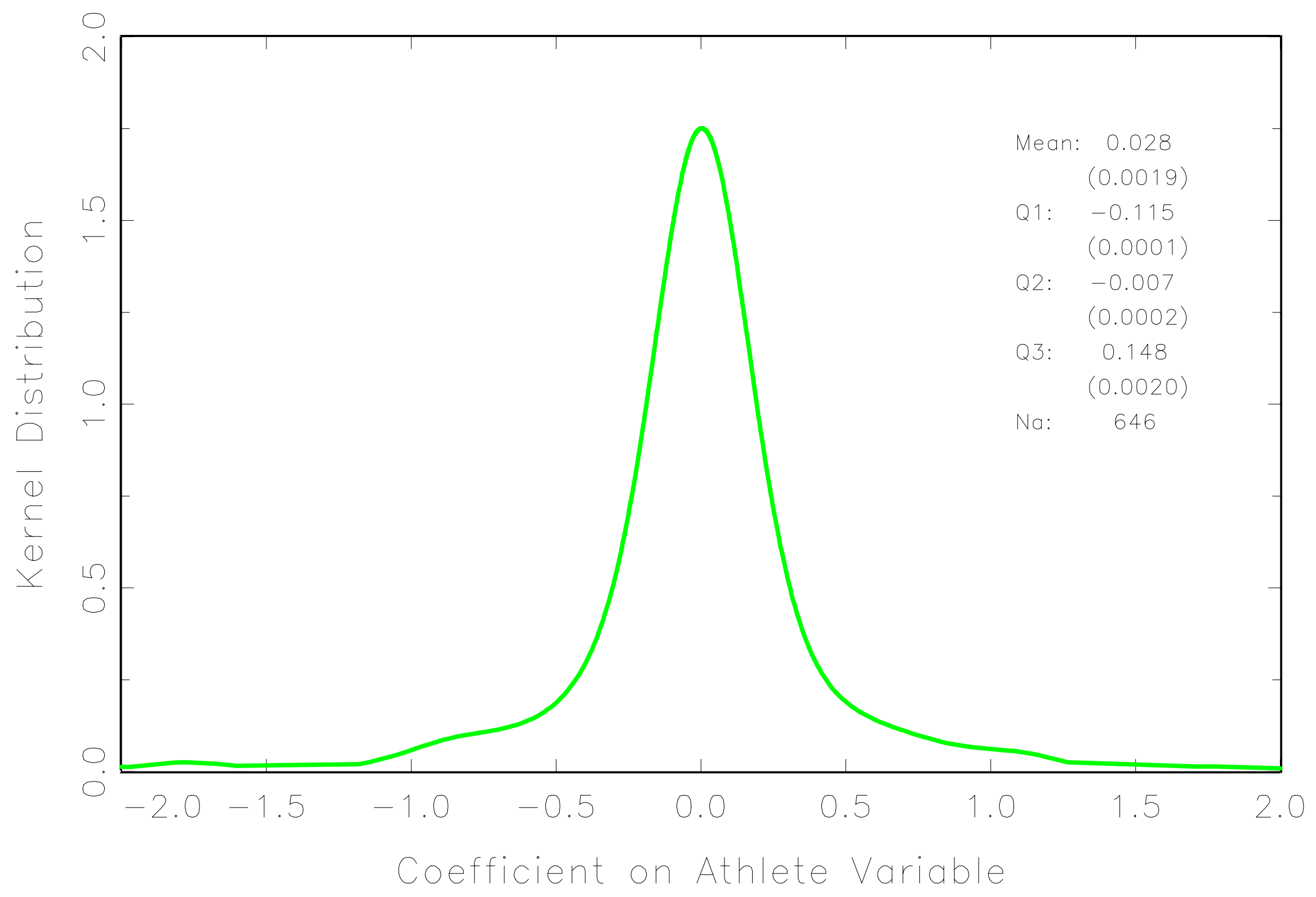


Appendix A: Variable Definitions

\begin{tabular}{ll}
\hline \hline Variable & Meaning \\
\hline ACT Score & Score on American College Test (range from 9 to 30) \\
African American & 1 if African American, 0 otherwise \\
Athlete & 1 if earned a varsity letter in college, 0 otherwise \\
Bachelor's Degree & 1 if holds bachelors degree, 0 otherwise \\
Business & 1 if individual reported occupation as business clerical, business management \\
& or business sales, 0 otherwise \\
Drive Dummy & 1 if individual rates themselves in the highest 10 percent to "drive to achieve" \\
Family Dummy & 1 if an individual reported that having a family was an important goal, 0 otherwise \\
Firm Size & Number of employees in firm individual works for, reported in categories \\
Grades & Self reported average college grades (A to F scale) \\
Manual Labor & 1 if individual reported occupation as skilled, semi-skilled or unskilled labor, 0 \\
& otherwise \\
MAJXX & Represents various college majors (See Appendix C) \\
Married & 1 if married, 0 otherwise \\
Masters Degree & 1 if holds masters degree, 0 otherwise \\
Military & 1 if individual reported occupation as military career, 0 otherwise \\
Number of Children & Number of offspring \\
OCCXX & Represents various occupations (see occupations list) \\
Part-Time Employed & 1 if an individual was employed part-time, 0 otherwise \\
Ph.D. or Professional degree & 1 if holds Ph.D. or advanced professional degree, 0 otherwise \\
Private & 1 if college attended was a privately owned institution, 0 otherwise \\
Runbus & 1 if an individual reported that owning their own business was a goal, 0 otherwise \\
School Enrollment & Total enrollment of college, reported in categories \\
Self Employed & 1 if individual was self-employed, 0 otherwise \\
Teacher & 1 if individual reported occupation as secondary or elementary teacher \\
Veteran & 1 if military veteran, 0 otherwise \\
Well Dummy & 1 if "being well off financially” is an important goal, 0 otherwise \\
\hline \hline
\end{tabular}


OCC1: 1

OCC2: 15, 25, 29, 30, 31, 40

OCC 3: 43 thru 47

OCC 4: 17

OCC 5: 23, 28, 35, 37

OCC $6: 6,7,8$

OCC 7: 2, 4, 27, 41

OCC 8: 3

OCC 9: 11, 13, 34, 36

OCC10: 14,18

OCC 11: 19, 22, 24, 26

OCC 12: 12

OCC 13: 9, 10

OCC 14: 16, 21

OCC 15: 42

OCC 16: 5

\begin{tabular}{llll}
\hline 1 & Accounting & 25 & Lawyer \\
2 & Actor/Entertainer & 26 & Military Service \\
3 & Architect & 27 & Musician \\
4 & Artist & 28 & Nurse \\
5 & Business Clerical & 29 & Optometrist \\
6 & Business Management & 30 & Pharmacist \\
7 & Proprietor & 31 & Physician \\
8 & Business Sales & 32 & School Counselor \\
9 & Clergy & 33 & School Principal \\
10 & Other Religious & 34 & Scientific Researcher \\
11 & Psychologist & 35 & Social Worker \\
12 & College Teacher & 36 & Statistician \\
13 & Computer Programmer & 37 & Therapist \\
14 & Conservationist or Forester & 38 & Teacher (Elementary) \\
15 & Dentist & 39 & Teacher (High School) \\
16 & Dietician/Home economics & 40 & Veterinarian \\
17 & Engineer & 41 & Writer/Journalist \\
18 & Farmer/Rancher & 42 & Skilled Trades/ Skilled Manual Labor \\
19 & Foreign Service Worker & 43 & Other \\
20 & Homemaker & 44 & Unskilled Worker/Unskilled Manual Labor \\
21 & Interior Decorator & 45 & Semi-Skilled Worker/Semi-Skilled \\
22 & Interpreter & & Manual Labor \\
23 & Lab Technician & 46 & Other Occupation \\
24 & Law Enforcement & 47 & Unemployed \\
\hline \hline
\end{tabular}


Appendix C: Definitions of Majors

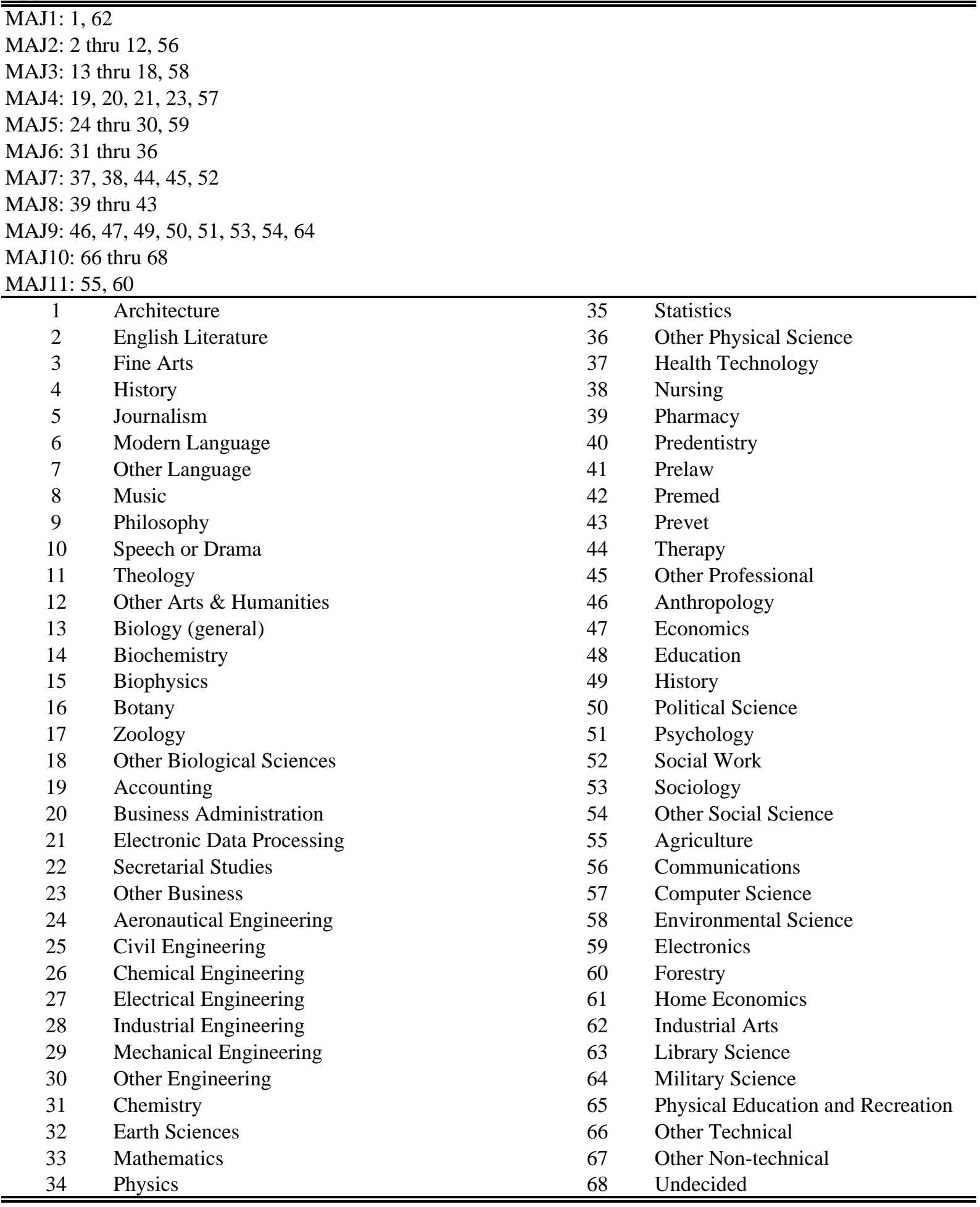

